\title{
The female perspective: Gender in cardiothoracic surgery
}

Nancy A. Nussmeier, MD

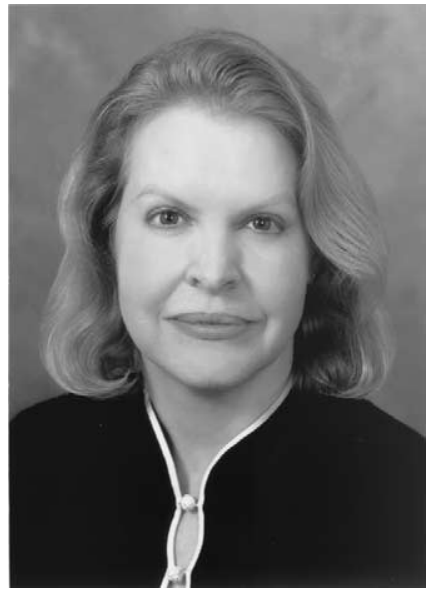

Dr Nussmeier

See related editorials on pages 617 and 620.
From the Department of Cardiovascular Anesthesiology, Texas Heart Institute at St Luke's Episcopal Hospital, Houston, Tex.

Received for publication June 3, 2003; accepted for publication July 7, 2003.

Address for reprints: Nancy A. Nussmeier, MD, Director of Cardiovascular Anesthesia Research, Texas Heart Institute at St Luke's Episcopal Hospital, 6720 Bertner Ave, Room O-520 (MC 1-226), Houston, TX 77030 (E-mail: nnussmeier@heart.thi. tmc.edu).

J Thorac Cardiovasc Surg 2003;126:618-9

Copyright (C) 2003 by The American Association for Thoracic Surgery

$0022-5223 / 2003 \$ 30.00+0$

doi:10.1016/S0022-5223(03)01202-9

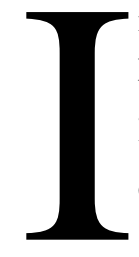

$\mathrm{n}$ upcoming issues of the Journal, a provocative series of editorials will be presented by a panel of cardiac, thoracic, and vascular surgeons, cardiologists, and cardiac anesthesiologists who are unique in that they are all women. The common thread in this series has nothing to do with political correctness or feminism, but rather with their particular insights and perspectives of thoracic and cardiovascular diseases from the same body of knowledge available to all physicians. Their focus will be on gender differences in disease patterns and responses to therapy, the paradoxes, the possible reasons, and the unknowns. Some of the editorialists are young, some are eminent, but all have carefully contemplated the issue of gender differences and will share their biases.

A generalization of many in the field is that women presenting for cardiac surgery are somehow "more difficult" to treat than men, both surgically (owing to smaller size) and medically (owing to more comorbidities). Nevertheless, women must have certain advantages since they outlive men by 5 to 7 years; in fact, nearly $60 \%$ of all 60-year-olds are women. ${ }^{1}$ Since women now have a life expectancy of about 80 years, aggressive treatment of all disease in older and sicker women is becoming the norm, as it should be.

The initial editorials concern coronary artery disease. There is still much debate regarding whether difference in mortality between men and women after coronary artery bypass $(\mathrm{CABG})$ surgery is due to female sex per se or to a higher prevalence of unfavorable risk factors in women by the time they present for cardiac surgery. Although the greatest risk seems to be postoperative, recent data show improved short-term outcomes for women after CABG surgery. ${ }^{2}$ But women still have more perioperative transfusions; longer periods of postoperative ventilatory support; more instances of postoperative heart failure; and, possibly, longer lengths of hospital stays and more difficult recoveries than men. Whether the latter is related to older age, more comorbidities, or more prevalent widowhood with lesser income remains speculation. A further enigma is the apparently higher postoperative mortality in younger $(<50$ years old) women who undergo $C A B G$ as compared with younger men, ${ }^{3}$ as if some protective factor normally present in younger women is lacking in those who require surgical treatment.

In later issues of the Journal, editorials will address gender factors in heart diseases other than ischemia, such as appropriate surgical procedures for patients who are or plan to become pregnant and appropriate cardiac valve procedures in women of small size. Gender differences in patterns of disease and appropriate treatment will also be reviewed for carotid artery disease, abdominal aortic aneurysm, and infrainguinal occlusive disease, for example, whether smaller arteries lead to lesser opportunity for endovascular procedures or more complications due to decreased graft patency. In another issue, the editorialists will discuss the differences between men and women in the clinical spectrum of heart failure, as well as limitations in surgical options for women in the selection of circulatory assist devices. Thoracic surgical disease will be the focus of the final issue in the series and will include a discussion of the markedly increased incidence of tobacco use, of cancer, and other pulmonary diseases among women.

The intent behind this series addressing "gender issues" in thoracic and cardiovascular disease is to pique your interest, instigate further dialogue, and stimulate future studies to explain perceived differences between men and women and to correct any disparities in treatment when found. Ideally, gender-specific risk factors 
can be mitigated and gender-specific protective factors can be exploited, thereby improving outcomes for all patients.

\section{References}

1. Gist YJ, Velkoff VA. Gender and aging: demographic dimensions. Vol 3. Washington (DC). US Department of Commerce; 1997 p 1.
2. O'Rourke DJ, Malenka DJ, Olmstead EM, Quinton HB, Sanders JH Jr, Lahey SJ, et al. Improved in-hospital mortality in women undergoing coronary artery bypass grafting. Ann Thorac Surg. 2001;71:507-11.

3. Vaccarino V, Abramson JL, Veledar E, Weintraub WS. Sex differences in hospital mortality after coronary artery bypass surgery. Evidence for a higher mortality in younger women. Circulation. 2002;105:1176-81 